\title{
MI MAESTRO ANTONIO DE BETHÉNCOURT Y MASSIEU
}

Manuel Lobo Cabrera

Universidad La Laguna 
El Departamento de Historia Medieval y Moderna de la Universidad Nacional de Educación a Distancia (UNED), donde han transcurrido los últimos años de la labor docente e investigadora de $\mathrm{D}$. Antonio de Bethéncourt y Massieu, nos solicita que presentemos el volumen homenaje a su figura. Hemos aceptado con mucho gusto porque estimamos que este Departamento y la propia UNED han reconocido en toda su dimensión la labor de nuestro amigo y maestro con la propuesta de concesión de la Medalla de Oro, el nombramiento de profesor Emérito y la celebración de este homenaje.

El haber aceptado este encargo constituye para nosotros in reto, porque glosar en pocas páginas la figura de Antonio de Bethéncourt es tarea harto difícil, pues no es nada fácil hacer la presentación de una persona de tan dilatada labor, aún cuando continúa en plena actividad docente, investigadora y publicística. A esto debe ser añadida su preocupación por la Universidad, allá donde ha ido, y demostrada a través de sus cargos académicos.

Difícil, porque su labor ha sido fecunda y porque para nosotros D. Antonio, como todos sus discípulos le llamamos, además de ser nuestro maestro, a quién le debemos el amor por la Historia de Canarias y el habernos introducido en el camino de la Historia Universal, es una persona entrañable, conversador incansable, partícipe de nuestras inquietudes, orientador de nuestra labor y a veces, incluso, confesor. Por todo ello la presentación de este volumen, que ahora los historiadores tienen entre sus manos, supone no sólo un honor sino un privilegio. 


\section{EL HOMBRE}

Nacido en el propio corazón de Las Palmas de Gran Canaria, en el viejo barrio de Vegueta, sintió siempre un profundo amor a su tierra, a sus costumbres y a sus gentes. Su vida está marcada por infinidad de anécdotas de la sabiduría popular que fue conociendo en su propia casa $y$ en sus andanzas por los distintos pueblos de la Isla. Sus estudios superiores los realiza en Madrid, donde se licencia en Filosofía y Letras por la Universidad Complutense, y donde asimismo se doctora en 1953 con premio extraordinario. La obtención del último título que concede la Universidad Española le habilita perfectamente para la docencia e investigación, desempeñando las mismas en las Universidades de Valladolid, de La Laguna y la UNED, aún cuando también prestó servicios en las Universidades de Santiago y Madrid, desde 1949 a 1954. Al tiempo, en 1954, obtiene el Premio de Investigación "Menéndez Pelayo", y es Colaborador del Consejo Superior de Investigaciones Científicàs (Instituto Jerónimo de Zurita).

De su talla humana hemos sido partícipes durante su estancia en la Universidad de La Laguna, donde fue catedrático desde 1967 a 1980. En estos años, amén de su magisterio, del que ya nos ocuparemos, D. Antonio dio muestras no sólo de su saber sino también de su generosidad y humanidad.

Tuvimos la suerte de conocer a D. Antonio en el examen de la prueba de madurez celebrada en Las Palmas en el verano de 1971. La impresión que nos causó a mí y a mis compañeros fue la de un Catedrático duro y exigente, pero los años nos demostraron cuán errados estábamos. Tropezamos con él nuevamente en La Laguna, pues ambos vivíamos en el Colegio Mayor San Fernando, y ahí comprendimos que aquel presidente de tribunal respiraba humor, canariedad y "socarronería» por los cuatro costados. Las tertulias en donde participaban colegiales del colegio en su compañía eran de las más amenas, donde la anécdota servía para enseñarnos distintos puntos de vista sobre la vida y la ciencia. Recordamos una en donde $D$. Antonio rememoraba la plática de un cura rural, el cual atribulado ante el problema de la Santísima Trinidad buscó un símil cotidiano para comparar el citado misterio con una pieza interior masculina, que se reducía a un solo artículo con tres agujeros. 
No tuvimos, sin embargo, la suerte de conocerlo directamente en el aula, donde impartía por entonces Historia Económica. No obstante, cuando cursábamos el quinto curso de la licenciatura y realizábamos con la Dra. Noreña Salto, adjunta del Departamento, un trabajo de investigación, basado en los protocolos notariales, sobre El Trabajo Asalariado en Gran Canaria, llegó a su conocimiento la realización del mismo. Enseguida se interesó por el trabajo, con esa curiosidad intelectual permanente que le caracteriza, y se puso en contacto conmigo. En aquellos momentos realizábamos nuestra memoria de licenciatura con la Dra. Marrero sobre protocolos notariales, siendo nuestro más ferviente admirador, porque siempre decía que todo modernista lo primero que debe hacer es conseguir el adiestramiento en las letras procesal y cortesana como herramientas indispensables para desentrañar el pasado histórico. De este modo y bajo la dirección de nuestra tesis doctoral caímos en las redes de la Historia, de la mano de D. Antonio, para iniciarnos en el arduo, pero apasionante mundo, de la ciencia histórica. Éste, el nuestro, es un ejemplo para colocar a D. Antonio en su contexto. Pero igual que hizo con nosotros, sabemos hizo con tantos otros compañeros, hoy profesionales de la Historia.

A todos, a través de conversaciones de pasillo, sentados delante de la barra de un bar, paseando por los entrañables rincones de La Laguna y de Las Palmas, e incluso quitando horas a sus obligaciones familiares y de responsabilidad, nos atendía, y es encomiable señalar que no todos los investigadores salieron de sus aulas, sino muchos se formaron y se entusiasmaron a través de su talante que demostró en todo momento, incluso en los más difíciles, mediando ante los responsables del orden público para interesarse por sus alumnos y obtener en algunos casos su liberación.

Su amor a la tierra también hizo que se preocupara por otras cuestiones extrauniversitarias. Pregonero incansable, recorrió las islas con su palabra en fiestas y tradiciones, lo mismo que a través de la prensa, pues siempre estuvo dispuesto a hacer labor fuera de las aulas, y a preocuparse por los temas insulares de actualidad.

\section{EL MAESTRO}

En las tres Universidades donde ha desempeñado su labor docente, ha dejado huella de su magisterio, tanto a través de sus clases de His- 
toria de España, Historia de América, Historia Económica, como Historia Moderna Universal y de España, como de director de numerosas memorias de licenciatura y de tesis doctorales, demostrando aquí su verdadera maestría. El resultado de las mismas y la profesionalidad de sus autores, casi todos profesores universitarios, hablan por sí solo de su buen hacer como historiador y como creador de escuela.

De su labor en Valladolid es una muestra más que fehaciente, en cuanto a tesis doctorales se refiere, el trabajo de Teófanes Egido ${ }^{1}$, con un notable prólogo de D. Antonio, estudioso del siglo XVIII. Pero quizá la etapa que mejor conocemos de $D$. Antonio es la canaria, a través de su magisterio en la Universidad de La Laguna, donde ha formado una pléyade de historiadores tanto de moderna, como de contemporánea, como de América.

A partir de su toma de posesión como Catedrático de Historia Moderna de La Laguna tuvo como meta la formación de un grupo de historiadores que aunaran esfuerzos para desentrañar la historia regional, pero con una preocupación clara que puso de manifiesto él mismo cuando dijo «no quisiéramos en el futuro dar una muestra estrecha, exclusivamente limitada al horizonte de nuestras islas, sino otro bastante más amplio, como pueda ser el de las interrelaciones de las mismas con su mar circundante y los continentes" ${ }^{2}$. Inquietud ésta que mantuvo durante la labor que realizó en Canarias, y que sigue realizando, en casi tres lustros. En ello coincidió además la creación de la Sección de Historia, la asunción por su parte como Director de la Revista de Historia de Canarias y la renovación de la Ciencia Histórica centrando su atención en los estudios sobre Economía, Sociedad y Mentalidad. En esta línea fue consciente de que era necesario primar estudios y monografias de ámbito local o comarcal, de acuerdo con la nueva metodología, para al cabo del tiempo llegar a consideraciones generales y a conseguir conclusiones de largo alcance. Con estos presupuestos y contando con que el interés por la Historia de Canarias ya se había iniciado bajo el Dr. Serra Ráfols, D. Antonio se preocupó no sólo por agrupar en torno a él a un grupo de historiadores, pues como él mismo manifestaba en 1971 «es imprescindible integrar dentro del cuerpo de colaboradores a todos los

T. EGIDO: La opinión pública y la oposición al poder en la España del siglo xvill, Valladolid 1971

"A. de Bethéncourt: "Preámbulo: Nueva orientación de la Revista de Historia", Revista de Historia, 169, La Laguna 1971-1972, pág. 3. 
miembros del Departamento de Historia Moderna y Contemporánea que se interesen por los temas insulares" ${ }^{3}$, si no a formar el propio Departamento, consiguiendo en pocos años que la Biblioteca del mismo fuera una de las más importantes, tanto en fondos como en temática.

Con ambos elementos, humano y material, comenzó a roturar el pasado insular, dirigido en dos direcciones: Historia Moderna y Contemporánea. Así fue como formó una generación de investigadores, que amén de las áreas ya citadas, se dedicaron también por la Historia de América y por la Historia Económica. Todos ellos, pues, profesionales de la Historia.

En relación a la Historia Moderna, hemos de decir que se incorpora más tarde a su quehacer, quizá como él mismo apunta porque resultaba que «el archipiélago en la Edad Contemporánea era mucho peor conocido que durante la Modernidad", y, además, porque adquirió plena conciencia sobre «la necesidad perentoria del conocimiento científico de nuestro pasado mediato" si se queria entender la realidad presente ${ }^{4}$, pero no por ello menos fructífera. El propio período histórico, más dilatado, y las preferencias y formación de sus alumnos, hizo que se acometieran diferentes flancos para alcanzar en estos momentos la publicación de varios libros, dirigidos y prologados todos ellos por D. Antonio.

La temática abarcada, a la cual ha prestado su apoyo más su agudeza de ingenio y visión y crítica histórica para orientarla, habla por sí sola.

El inicio de una tesis sobre el siglo $\mathrm{XVI} \mathrm{I}^{5}$, obra nuestra, y el empuje dado para continuar en esa línea, tanto desde la óptica económica, como social y mental, han permitido que este siglo sea mucho más conocido ahora, que antes del comienzo del citado trabajo.

El siglo XVII, denominado por D. Antonio «auténtico Siglo de Oro» para Canarias, gracias a su peculiar olfato de historiador, ya ha comen-

${ }^{3}$ Idem, pág. 4.

${ }^{4}$ A. BETHÉnCOURT Y MASSIEU: Investigación Universitaria y la Masonería en Canarias, prólogo al libro de M. de PAZ SÁNCHEZ: La Historia de la Francmasonería en Canarias (17391936), Las Palmas 1984, pág. XV.

${ }_{5}$ M. Lobo Cabrera: La esclavitud en las Canarias Orientales en el siglo XVi (negros, moros y moriscos), Las Palmas 1982. 
zado a cubrirse en parte, bajo su dirección, por E. Torres Santana ${ }^{6}$. Lo mismo podemos decir del Siglo de las Luces, con similar trayectoria y con logros en el campo social, económico, religioso, cultural y mental gracias a las aportaciones de V. Suárez Grimón, J. Escribano y F. Fajardo ${ }^{7}$, que amén de prestar mayor atención al siglo XVIII, arrancan desde el Quinientos y llegan incluso hasta la transición del Antiguo Régimen.

En esta línea ya comentada se encuentra la tesis de A. Macías, que estudia el modelo socio-económico del Archipiélago en el Antiguo Régimen $^{8}$.

Todo este grupo de historiadores canarios, bajo su sabia dirección, hablan de su entrega al estudio y a la Universidad, consiguiendo a través de su escuela, a la que enseñó a superar conceptos y a plantear problemas e hipótesis de trabajo, que en no muchos años nos encontremos con el campo roturado para realizar una Historia de Canarias. Pero no sólo esto es lo importante, sino que además nos ha dotado de un método puesto al día en consonancia con lo que se realiza en España y en Europa. La Historia Contemporánea es la otra área a la cual D. Antonio prestó bastante atención dentro de la historia regional canaria, a pesar de su especialidad. Aquí se abarcaron dos líneas prioritarias. Por un lado el aspecto político iniciado con el trabajo de A. Sánchez Enciso que abarcaba el sexenio revolucionario ${ }^{9}$, y de otro la aportación de T. Noreña sobre la historia regional de Canarias en el período de la Restauración ${ }^{10}$, trabajo en donde, en su prólogo, D. Antonio pondera el valor de dicha historia al señalar "Historia regional sí, pero con un profundo conocimiento de lo que ocurre fuera de las islas, con el fin de no descubrir mediterráneos. Historia regional sí, pero agotando previamente la litera-

- M. E. Torres Santana: Comercio y burguesía mercantil en las Canarias Orientales en el primer cuarto del siglo XVII, La Laguna 1987 (Tesis doctoral inédita).

7 V. SuÁrez Grimón: La propiedad pública, vinculada y eclesiástica en Gran Canaria, en la crisis del Antiguo Régimen, Las Palmas 1987, 2 vols.; J. Escribano Garrido: Los Jesuitas y Canarias 1566-1767, Granada 1987; F. FAJARDO SpInOLA: Reducciones de protestantes al catolicismo en Canarias durante el siglo XVHI: 1700-1812, Las Palmas 1977.

8 A. MACIAS HERNÁNDEZ: Economía y sociedad en Canarias durante el Antiguo Régimen (1520-1830), UNED, 1985 (Tesis doctoral inédita).

9 La tesis del profesor A. SÁNCHEZ DE ENCISO Y VALERO ha dado origen a dos libros: Las Juntas Revolucionarias canarias de octubre de 1868, La Laguna 1984, y Republicanismo y republicanos durante el sexenio revolucionario.

10 T. Noreña Salto: Canarias: Política y sociedad durante la Restauración, Las Palmas 1977, 2 vols. 
tura teórica sobre la época, la realidad nacional y la de otras regiones españolas, para poder con seguridad deslindar y contrastar los rasgos caracterizadores de otros que fueron comunes a entidades regionales, nacionales o continentales» ${ }^{11}$.

Por otro, la dirección se centró en estudios sociológicos importantes, hacia tres campos claves. Por una parte hacia el estudio de la aparición $y$ trayectoria del movimiento obrero canario ${ }^{12}$, por otra un tema a caballo entre la propia Historia Contemporánea y la Historia de América, como es el de la emigración canaria a América en el siglo XIX, realizado por J. Hernández, y finalmente hacia el análisis de la Francmasonería, tema inédito dentro de la historiografía canaria como señala $D$. Antonio en el notable prólogo de la obra ${ }^{13}$.

Hasta aquí la labor de D. Antonio durante su estancia en Canarias, labor que no ha sido interrumpida durante sus años en Madrid, pues desde allí y a través de sus breves descansos en Canarias continúa enriqueciendo y orientando tres tesis que en breve podrían completar su magisterio ${ }^{14}$.

La inquietud de este hombre, profesional de la historia, no se paraliza sino al contrario se dispara en la nueva cátedra de la UNED, comenzando a roturar nuevos campos de la historia por toda la geografía española, en función de la propia estructura de la Universidad a Distancia. En poco menos de ocho años ha dirigido más de sesenta tesinas, casi el triple de las orientadas durante su período lagunero, y ocho tesis que abarcan estudios desde el País Vasco a Andalucía pasando por Galicia, Cataluña y Aragón, sin abandonar la orientación de temas institucionales ni bibliográficos.

Además estas tesis tienen una peculiaridad, pues en gran medida están acotadas dentro de su especialidad. Como gran conocedor del siglo XVIII español, algunas están orientadas en este sentido, como por

11 ldem, pág. 7.

12 O. BRito GonZález: Historia del movimiento obrero canario, Madrid 1980.

${ }^{13}$ J. HeRnández Garcia: La emigración de las Islas Canarias en el siglo xIX, Las Palmas 1981, y M. de PAZ SÁnCHEZ: Op. cit.

${ }_{14}$ Los autores y títulos de estas tesis son: F. FaJARDo SPINOLA: Brujería e Inquisición; J. GONZALEZ DE ChAVESY MENENDEZ: Mentalidad y comportamiento religioso en el setecientos, y A. Millares Cantero: El partido republicano federal de España tras la muerte de Pi y Margall. 
ejemplo la de D. A. Gracia Guillén sobre las Reformas borbónicas en la Universidad de Huesca ${ }^{15}$. No obstante también se concentra hacia la dirección de estudios que arranquen desde el siglo XVI para concluirlos en la crisis del Antiguo Régimen. La riqueza de los temas habla de su sagacidad como historiador, conectados algunos de ellos con su línea de trabajo: La vida municipal en La Coruña en el siglo XVI, La "Taula de Canvi» de Cervera ${ }^{16}$, la industria textil abulense y el problema de la tierra en Cabra ${ }^{17}$ son ejemplos más que significativos, unidos a otros donde los estudios son más globales tanto a nivel provincial como nacional, tales como La provincia de Álava, $1750-1814^{18}$, y el Estudio comparativo de los tribunales inquisitoriales entre 1540-1621 ${ }^{19}$.

A estos estudios, novedosos e importantes, tanto por el tema como por el propio contenido, se ha de añadir la tesis de J. A. Moreiro sobre la personalidad del erudito, filólogo, bibliófilo y humanista canario D. Agustín Millares Carlo ${ }^{20}$.

La labor, por tanto, de D. Antonio, alli donde ha estado, no tiene desperdicio, si a ello unimos las tesinas y trabajos individuales que ha orientado y criticado con esa mente ordenada para enriquecerlos. Además es de señalar que con esas virtudes ya señaladas sabe llegar a sus alumnos para inculcarles que allí donde se haga la Historia es una sola.

Finalmente, queremos señalar que todas las tesis leídas bajo su dirección han merecido para los tribunales que las han juzgado la calificación de Sobresaliente Cum laude, además de haber conseguido con ellas muchos de sus autores Premios extraordinarios y Premios de Investiga-

15 J. A. Gracia GullLÉn: Las Reformas borbónicas en la Universidad de Huesca, UNED, 1987 (Tesis doctoral).

${ }^{16}$ I. Velo Pensado: La vida municipal de La Coruña en el siglo XVI, UNED, 1988; J. Llovet Portela: La "Taula de Canvi" de Cervera y su entorno socioeconómico, Lleida 1984.

17 G. Martin Garcia: La industria textil abulense en la crisis del Antiguo Régimen: La Real Fábrica de algodón, UNED, 1987 (Tesis doctoral inédita); J. CAMERo Ramos: El problema de la tierra en Cabra (Córdoba), 1752-1852, UNED, 1987 (Tesis doctoral).

${ }^{18}$ C. LIZURDAY INIIGUEZ: La provincia de Álava (1750-1814), UNED, 1989 (Tesis doctoral inédita).

19 A. Acosta GonzÁlez: Estudio comparativo de los tribunales inquisitoriales. Período 1540-1621, UNED, 1989 (Tesis doctoral inédita). Este autor bajo la dirección del profesor Bethéncourt realizó anteriormente su tesina sobre La Inquisición en Canarias durante el siglo XVI (aproximación histórico estadística), UNED, 1985. 1989. 
ción, concretamente cuatro han sido premiadas con el "Viera y Clavijo", más haber visto la luz como publicaciones, todas, salvo dos, una por lo voluminosa y otra por lo reciente.

\section{EL INVESTIGADOR}

La labor investigadora del profesor Bethéncourt ha ido pareja con su magisterio, comenzando aquélla desde el momento que realiza su doctorado y continuando luego en una dilatada brecha sus investigaciones en varios frentes. La obra de $\mathrm{D}$. Antonio tiene el mérito no sólo de la investigación puesta al servicio de los historiadores sino la amenidad de la misma, escrita con soltura, de ahí el interés también de sus escritos, salpicados con notas de humor e ironía, aspecto éste propio de su personalidad y de su «ser» canario.

Las líneas de investigación de este profesor universitario se pueden dividir en dos, con ramificaciones hacia la economía, la política, la sociología, concentradas en gran parte en el siglo de las Luces, del cual es un gran conocedor.

De una parte, estudia el período del primer Borbón español en relación con el exterior, para concentrarse luego en la figura del ministro de Felipe V, José de Patiño ${ }^{21}$, libro base para conocer sus actividades como Ministro Intendente general de la Armada, superintendente del reino de Sevilla y presidente del tribunal de Contratación, en 1717. Quizá la figura de este personaje, primero de la serie de grandes ministros del XVIII español junto con Campillo, Carvajal, Ensenada, Aranda y Floridablanca, y su gran labor en la Marina, fue básica para la serie de estudios que realizó $\mathrm{D}$. Antonio en relación al mar, a la construcción naval, y al mejoramiento y creación de arsenales, con la serie de trabajos que realiza en adelante, unos circunscritos al reinado de Felipe $\mathrm{V}$, otros al de Fernando VI y al de Carlos III, relativos tanto a la Península como a la América hispana y portuguesa, tales como el Proyecto de establecimiento ruso en

${ }^{21}$ Patiño en la política exterior de Felipe V, Valladolid 1954. Su tesis leída en 1953 versa sobre Política exterior de Felipe $V$. 
Brasil $^{22}$, Felipe $V$ y La Florida ${ }^{23}$, El Real astillero de Coatzacoalcos ${ }^{24}$, Arboladuras de Santa María de Chimalapa (Tehuantepec) en las construcciones navales indianas, $1730-1750^{25}$, y El Escorial y el arsenal de Cartagena ${ }^{26}$, completados con el estudio sobre El Marqués de la Ensenada y la Arqueología ${ }^{27}$.

En esta misma línea de investigación del siglo XVIII se encuadra su obra sobre El catolicismo en Gibraltar durante el siglo XVIII ${ }^{28}$. No obstante el tema de la llamada Punta de Europa ya había interesado a D. Antonio, preocupándose por el estudio del Peñón desde su incorporación a la corona castellana en la segunda mitad del siglo $\mathrm{xv}^{29}$. Estos trabajos le harían reflexionar más tarde, poniéndolos al día con nuevas perspectivas ${ }^{30}$.

El otro gran filón de la historiografía realizada por el profesor Bethéncourt es el de la Historia de Canarias. Se interesa por el mismo mucho antes de su incorporación a la Cátedra de La Laguna, por su condición de canario, demostrando que se podía trabajar sobre Canarias desde fuera sirviéndose de los Archivos Nacionales, poco explotados hasta ese momento, a excepción del profesor Rumeu de Armas. Comienza con un trabajo de orientación económica sobre el comercio del vino entre Canarias e Inglaterra ${ }^{31}$. Este estudio es una descripción detallada, razonada y claramente expuesta del desarrollo de este comercio durante los siglos XVII y XVIII. Comienza por el análisis de los diferentes mercados y cómo se decanta el inglés respecto a los demás (Portugal, Indias, Imperio Británico en América). Los ingleses vendían paños, manufacturas, arenques y otros productos de lujo a cambio de pago en vino, moneda $u$ orchilla, al tiempo que les servía de plataforma para el contrabando con

22 Revista de Indias, Madrid 1949, págs. 651-669.

${ }^{23}$ Anuario de Estudios Americanos, Sevilla 1950, págs. 95-123.

${ }^{24}$ Anuario de Estudios Americanos, Sevilla 1958, págs. 371-428.

${ }^{25}$ Revista de Indias, Madrid 1960, págs. 65-103.

${ }^{26}$ Boletín Seminario Arte y Arqueología de Valladolid, Valladolid 1963, págs. 288-302.

${ }^{27}$ Boletín Seminario Arte y Arqueologia de Valladolid.

${ }^{28}$ Valladolid 1967.

${ }^{29}$ A. de BethénCourt y Massieu y L. Cano GardoquI: Incorporación de Gibraltar a la Corona de Castilla. 1463-1508, Hispania, Madrid 1965, págs. 325-382.

${ }^{30}$ "La comunidad católica de Gibraltar en el siglo xVII" ", Actas del Congreso Internacional El Estrecho de Gibraltar (1984), Madrid UNED, 1988, 4 vols. III, págs. 105-113.

31 "Canarias e Inglaterra. El comercio del vino, 1650-1800," Anuario de Estudios Atlánticos, 2, Madrid-Las Palmas 1956, págs. 195-308. 
América. Este trabajo de $\mathrm{D}$. Antonio ofrece una completa panorámica del comercio vinicola, siempre desde el punto de vista canario, con el análisis detallado de los acontecimientos y gestiones a las que dio lugar este producto isleño durante tres siglos ${ }^{32}$. Sobre este tema volvería a insistir posteriormente, diferenciando ya la coyuntura y política comercial del siglo XVII y del XVIII ${ }^{33}$.

Introducido ya en los temas económicos, amplía esta línea de investigación sin abandonar otras tan interesantes y novedosas como ésta. El estudio de la economía del archipiélago en el siglo XVIII ${ }^{34}$ le interesa sobremanera, ampliando su campo de acción a un análisis de la población y sus recursos ${ }^{35}$, para adentrarse en el problema de la tierra, tema vital para estudiar la economía del archipiélago, erizada de problemas y conflictos socio-económicos, que le orientaron hacia el estudio de los mismos, comenzando por el intento en tiempos de Carlos III de colonización de tierras en Gran Canaria, a petición de la misma isla, con un plan propuesto al ministro Floridablanca, quien impone como condiciones para ejecutarlo que «las nuevas poblaciones se ajustarían al modelo del Fuero publicado para Sierra Morena, el producto del moderado canon se destinaría a propios de las nuevas comunidades y sólo recibirían lotes pobres de solemnidad de la isla» ${ }^{36}$. Lo similar del modelo al ideado para Sierra Morena le llevaría a realizar una comparación entre éste y el proyectado para Canarias ${ }^{37}$. Vinculado al mismo tema y siempre dentro de la problemática de la tierra, del agua y de los conflictos jurisdiccionales se adentra

${ }^{32}$ M. Lobo Cabrera y E. Acosta Guerrero: El comercio canario. Estado de la cuestión. $\checkmark$ Coloquio de Historia Canario-Americano (1982), Sevilla 1985, t. III, pág. 89.

33 "Canarias y el comercio del vino (siglo $x$ vil)". Historia General de las Islas Canarias de A. Millares Torres, Las Palmas de Gran Canaria, T. III, págs. 266-273; Canarias y el comercio del vino (siglo XVIII), Idem, T. IV, págs. 145-180.

${ }^{34}$ "Economía y sociedad de las Islas Canarias en el siglo XVII", Campus O, La Laguna 1975, págs. 25-44; "Aproximación a la economía de las Islas Canarias», Revista Universidad Complutense, Madrid 1978, págs. 186-202; "La Economía de las Islas Canarias durante la llustración (1770-1808)", Homenaje a D. Jesús Pabón. Estudios de Historia Moderna y Contemporánea, Madrid 1978, I, págs. 186-202.

35 A. Bethéncourt Y MASSIEU y A. Macias HeRnández: «Expansión de cultivos y conflictos sociales en Gran Canaria en el tránsito del Antiguo al Nuevo Régimen", Historia General de las Islas Canarias de A. Millares Torres, Las Palmas de Gran Canaria 1979, T. IV, págs. 237-249.

${ }^{36}$ "Colonización interior en el SW de Gran Canaria a fines del siglo XVIII", Boletín Millares Carlo, /l, 1, Madrid 1981, págs. 141-156.

${ }_{37}$ «El modelo de Sierra Morena en Canarias. Un proyecto de Nuevas Poblaciones en el SW de Gran Canaria", Carlos III y las "Nuevas Poblaciones", Córdoba 1988, 3 vols. I, págs. 327-344. 
en el estudio de determinados motines y "asonadas", tales como el Agüímes ${ }^{38}$ y el de 1789 en Lanzarote ${ }^{39}$.

Estas investigaciones no le restan abrir nuevas líneas que van abarcando el estudio de distintos problemas en todas las islas del Archipiélago. Dedica especial interés al estudio de los ataques piráticos a las islas, concretamente a Fuerteventura, donde pone de relieve la derrota de los ingleses en esta isla en 1740 sorprendidos por los naturales que lanzan una manada de camellos enfurecidos contra ellos ${ }^{40}$. La importancia del trabajo, preparado actualmente para su segunda edición, con un largo estudio previo donde analiza, compara y diferencia el corso de la piratería, le permite reflexionar acerca de este ataque para incorporarlo al contexto de la guerra de corso en Canarias ${ }^{41}$, tema ya iniciado por Rumeu de Armas ${ }^{42}$.

En relación con esta misma isla publica un trabajo de carácter jurisdiccional eclesiástico, donde analiza por un lado el panorama de la asistencia pastoral canaria en el siglo XVIII y por otro el problema planteado por una parroquia de Fuerteventura para conseguir ser sede parroquial, culminando con una serie de conclusiones de interés donde destaca el papel desempeñado por el obispo Tavira, de formación ilustrada y de espíritu jansenista ${ }^{43}$.

El espíritu ilustrado y la política de Carlos III en consonancia con el regalismo y los presupuestos socioeconómicos de su equipo llevan a D. Antonio a continuar en esta línea con la publicación de dos artículos, uno relativo al cierre de hospicios ${ }^{44}$ y otro al fracaso de instalación de la orden Bethelemita en Canarias ${ }^{45}$.

38 «El Motín de Agüímes-Las Palmas (1718-1719)», Anuario de Estudios Atlánticos, 33, Madrid-Las Palmas 1987, págs. 51-159. En estos momentos este trabajo se encuentra en prensa, ampliado, para editarlo como libro, bajo los auspicios del Ilmo. Ayuntamiento de la Villa de Agüímes (Gran Canaria).

39 "Reflexiones sobre la "asonada" de Lanzarote en 1789", Anuario de Estudios Atlánticos, 34, Madrid-Las Palmas (en prensa).

40 Ataques ingleses a Fuerteventura. 1740, Fuerteventura 1965.

41 " "Los ataques a Fuerteventura" en el contexto de la guerra de corso en Canarias", Tebeto, 2, 1988 (en prensa).

42 A. RUMEU DE ARMAS: Piratería y ataques navales contra las Islas Canarias, Madrid 1947-1950.

43 "Evolución de las jurisdicciones parroquiales de Fuerteventura durante el siglo XVIII", Revista de Historia Canaria, 170, La Laguna 1973-1976, págs. 7-70.

44 «Política regalista en Canarias. El cierre de los hospicios franciscanos de Guía y La Matanza", Boletín Millares Carlo, III, 6, Madrid 1982, págs. 449-497.

${ }_{45}$ «Política regalista en Canarias. El fracaso de la instalación de los Bethlemitas", Anuario de Estudios Atlánticos, 29, Madrid-Las Palmas 1983, págs. 159-194. 
Ligados los antecedentes trabajos al mundo mental y cultural de las islas, siente preocupación por otros temas no menos interesantes abriendo una nueva línea de investigación: la enseñanza vista desde presupuestos históricos. En tres estudios ha puesto de relieve el papel de la misma en el archipiélago. En uno abarca el análisis de la enseñanza primaria en Canarias durante todo el Antiguo Régimen ${ }^{46}$, partiendo desde la enseñanza institucionalizada, para a continuación poner de relieve el papel jugado por las escuelas conventuales, las parroquiales, la financiación de las mismas y de otras y la calidad de la enseñanza impartida. Paralelos al tema son los artículos sobre la enseñanza en Tenerife en 1790 , donde hace hincapié en la financiación de las escuelas públicas ${ }^{47}$, y una jornada escolar en Las Palmas en $1775^{48}$.

Metido ya en la línea sociológica e incluso etnográfica el profesor Bethéncourt avanza por el camino de los estudios de tercer nivel. En uno de ellos no podemos por menos de reseñar una de las conclusiones a la que llega D. Antonio "Canarias, rompeolas de las novedades europeas y escena donde se mueven y alternan risueñamente viejos y nuevos modos» ${ }^{49}$.

Las peleas de galios en Tenerife en el Setecientos ${ }^{50}$, se inserta ya dentro de la etnografía. Los estudios sobre el tema, relativos al ocio y al espectáculo, han llamado la atención de los historiadores, sociólogos y antropólogos sociales, por permitir explicar claves del comportamiento colectivo. No obstante, al ser elementos del acontecer diario han dejado poca huella en la documentación, a no ser que intervengan los poderes oficiales. El tema en cuestión, que arranca desde la Edad Media castellana para ser trasplantado primero a Canarias y luego a América, ha podido ser reconstruido gracias a las disposiciones de la autoridad sobre el mismo, al ser legalizadas las peleas de gallos por Carlos IV, por con-

\footnotetext{
47 «La enseñanza en Tenerife en 1790. Situación y plan para financiar la dotación de Escuelas públicas», Revista de Historia Canaria, 174, La Laguna 1984-1986, págs. 33-61.

48 "Una jornada escolar en Las Palmas de Gran Canaria en 1775», Boletín Millares Carlo, V, 9-10, Madrid 1987, págs. 141-154

49 «El teniente corregidor de La Palma Luis Abadal y su "Androgino-Micomicona. ¿Oro en la Caldera?"',, Anuario de Estudios Atlánticos, 31, Madrid-Las Palmas 1985, págs. 277314.

50 "Las peleas de gallos en Tenerife en el siglo XVIIl», Anuario de Estudios Atlánticos, 28', Madrid-Las Palmas 1982, págs. 477-518. Este artículo por la novedad del tema mereció ser publicado como libro por el Aula de Cultura del Cabildo de Tenerife en 1987.
} 1985.

${ }^{46}$ La enseñanza primaria en Canarias durante el Antiguo Régimen, UNED. Las Palmas 
siderarlas un espectáculo y a la vez un entretenimiento dominguero para los ciudadanos de las islas.

La delincuencia, otro tema candente y de moda entre historiadores y sociólogos, también se encuentra entre sus líneas de trabajo. Esta línea de investigación hay que considerarla pionera en la historiografía canaria. El trabajo, circunscrito al reinado de Carlos III como otros suyos, pone de relieve varias cosas: por un lado la preocupación por un tema social, por otro la capacidad del equipo de gobierno de Carlos III para entender y asumir las peculiaridades de las Islas Canarias, y finalmente la conexión del tema con un ramo de vital importancia para el archipiélago y de larga tradición: la pesca ${ }^{51}$. Partiendo del régimen penal, lo conecta con la pesca en la costa de África, en el llamado banco canario-sahariano, para dar a conocer aspectos tales como la vida de los pescadores, las estructuras de las sociedades formadas para tal efecto, la conservación y reparación de las embarcaciones, la relajación de la disciplina, la asistencia espiritual de las tripulaciones, y la actitud de éstas ante la presencia de nuevos compañeros, con los problemas que éstos planteaban a bordo durante la condena ${ }^{52}$.

En general la temática abordada por $\mathrm{D}$. Antonio es amplia y diversa si a lo señalado añadimos otros estudios de carácter sanitario ${ }^{53}$, urbano ${ }^{54}$, político ${ }^{55}$, jurisdiccional ${ }^{56}$, geográfico ${ }^{57}$, e incluso crítico a través de la obra del escritor canario Pérez Galdós ${ }^{58}$. Pero incluso ha lle-

51 "Vagos y régimen penal en Canarias: la Real Cédula de 1770", Anuario de Estudios Atlánticos, 32, Madrid-Las Palmas 1986, págs. 447-482.

${ }_{52}$ «La pesca en la costa de África a la luz de la Real Cédula de 1770 sobre vagos y delincuentes en Canarias", "I Aula Canarias y el Noroeste de África, Las Palmas de Gran Canaria 1986, págs. $165-170$.

53 «El hospital de San Lázaro, el Doctor Cubas y el Cabildo de Gran Canaria (16471657)», Revista de Historia Canaria, 169, La Laguna 1971-1972, págs. 101-109; “Inoculación y vacuna antivariólica en Canarias. 1760-1830", V Coloquio de Historia Canario-Americana (1982), II, Las Palmas 1985, págs. 297-307.

${ }^{54}$ Santa Cruz de La Palma. Una ciudad insular en la crisis del Antiguo Régimen, "Serta gratulatoria in honorem Juan Régulo» III, La Laguna 1988, págs. 266-301; «Santa Cruz de La Palma en 1709. Un plano inédito y el cuidado de San Antonio de la Breña Baja", Anuario de Estudios Atlánticos, 35 (en prensa).

${ }_{55}$ "Canarias, Berbería e inquisición, 1578-1610. Aportaciones para un estudio", Homenaje a Elías Serra Ráfols, La Laguna 1973, I, págs. 223-248.

56 "Proyecto de incorporación de La Gomera a la corona real por Felipe II, 1570-1590", Anuario de Estudios Atlánticos, 14, Madrid-Las Palmas 1968, págs. 405-441.

57 "Los terremotos de 1793 en el Hierro", Homenaje a Alfonso Trujillo, S/C de Tenerife 1982, T. II, págs. 13-28.

58 "La Guerra Revolucionaria" en los Episodios Nacionales de Galdós, Madrid 1987. 
gado a más, al intentar desentrañar la política seguida con la documentación durante el Antiguo Régimen ${ }^{59}$.

La experiencia, el magisterio y su propia labor investigadora le han dado la suficiente madurez para que $D$. Antonio al cabo de tantos años de trabajo, solo y en unión de sus alumnos, pudiera elaborar una ponencia donde sentara las bases de la Historia de Canarias durante el Antiguo Régimen ${ }^{60}$. En ella realiza un recorrido desde la conclusión de la conquista hasta 1825, poniendo de relieve los hitos más importantes del período para llamar la atención sobre las lagunas existentes en el mismo, las dificultades con que se encuentra la Historia de Canarias y las bases para permitir desarrollar una escuela de historiografía regional, llamando la atención sobre la necesidad de crear una Asociación de Historiadores de Canarias y un Instituto de Estudios de Historia de Canarias.

Estas reflexiones sobre la Historia de Canarias no son nuevas, pues ya en 1971, pocos años después de su incorporación a La Laguna, al ser nombrado Director de la "Revista de Historia", planteaba las primeras sugerencias sobre el tema ${ }^{61}$, ampliadas posteriormente al realizar un estudio sobre las investigaciones históricas en el archipiélago tras el historiador Millares Torres, donde realiza un recorrido por la Prehistoria, los repertorios bibliográficos, las escuelas históricas, la labor de las revistas, y las nuevas tendencias, para concluir llamando la atención sobre la necesidad de "disponer en un plazo medio de las monografías imprescindibles que nos permitan acometer en equipo una historia regional, tal y como hoy es entendida y tal y como hoy la demandan las nuevas generaciones» ${ }^{62}$.

Completa su labor publicista el profesor Bethéncourt con los prólogos a las tesis, convertidas en libros, de sus alumnos, para quiénes es un honor que el nombre del maestro tigure junto con el suyo en la portada del mismo. En ellos, amén de introducir al lector en la propia obra, D. Antonio sitúa la obra en el marco donde se desarrolla el tema, profundizando en él. El primero que realiza sirve para encuadrar el trabajo de

59 "Salvamento y restauración del archivo de la Real Audiencia de Canarias (17691788)", Boletín Millares Carlo, II, 4, Madrid 1981, págs. 357-378.

${ }^{60}$ Canarias bajo el Antiguo Régimen, "Congreso de la Cultura Canaria. Sección Historia Moderna", La Laguna 1987.

${ }^{61}$ Preámbulo..., art. cit.

62 "Desarrollo de las investigaciones históricas tras Millares Torres", Historia General de las Islas Canarias de A. Millares Torres, Las Palmas 1977, T. I, págs. 53-74. 
T. Egido sobre el $\mathrm{XVIII}{ }^{63}$, y el mismo es calificado por especialistas más notorios que nosotros como de notable.

Siguiendo con la Historia Moderna hemos de destacar el prólogo a la obra La esclavitud en las Canarias Orientales en el siglo XVI, donde el prologuista realiza un estudio pormenorizado sobre la Panorámica del Quinientos canario ${ }^{64}$, ponderando la validez de los protocolos notariales como fuente histórica. En el desarrollo del mismo estudia los renglones económicos de Canarias, insertando en ellos el comercio de esclavos. Relativo a Canarias es también el que introduce el trabajo de V. Suárez Grimón ${ }^{65}$, para hacer un papel similar en los estudios sobre La «Taula de Canvis de Cervera ${ }^{66}$, o la Villa de Noya en la Edad Moderna ${ }^{67}$.

En Historia Contemporánea podemos verle seguir una línea similar en los libros de T. Noreña ${ }^{68}$, J. Hernández ${ }^{69}$ y M. de Paz ${ }^{70}$. Estos últimos le dan pie para profundizar por un lado sobre la emigración como una estructura de la Historia de Canarias dentro de la sociedad insular, marcando una periodización de la misma que abarca desde el siglo XVI al $x x$ y sus características, y por otro para reflexionar sobre la investigación en la Universidad de La Laguna y la Francmasonería.

Recientemente ha concluido el prólogo a la obra de J. A. Moreiro sobre el profesor Agustín Millares Carlo. En él D. Antonio destaca la figura de este canario universal, sobre todo en su papel como historiador de base ${ }^{71}$.

El papel de prologuista lo amplía, a veces, a otros libros de alumnos y discípulos suyos como son los de Agustín Millares Cantero ${ }^{72}$ y M. F. Núñez ${ }^{73}$. $\mathrm{V}-\mathrm{XXVI}$

${ }_{63}^{63}$ En torno a la opinión y al poder en la España setencista, en T. Egido: Op. cit, págs.

${ }_{64}$ M. Lobo Cabrera: Op. cit., págs. 9-32.

${ }^{65}$ V. SuÁrez Grimón: Op. cit., págs. 11-15.

${ }^{66}$ J. LLOVET PORTELA: Op. cit., pág. 14.

${ }^{67}$ M. L. de VITORIA: La villa de Noja en la Edad Moderna: una aproximación a su historia, Noja 1987, págs. 11-18.

${ }_{68}$ T. NORENA SALTO: Op. cit, págs. 3-7.

${ }^{69}$ La emigración: una estructura en la Historia de Canarias, en J. HeRnández García: Op. cit., págs. 11-24.

${ }_{70}$ Investigación universitaria y la francmasonería en Canarias. Reflexiones, en M. de PAZ SÁnCHEZ: Op. cit., págs. XIII-XXXIII.

${ }^{71}$ Agustín Millares Carlo, un historiador de base, en J. A. MoreIro GonzÁlEz: Op. cit., págs. 21-35.

${ }_{72}$ Interpretación de una fenomenología de la Restauración en Gran Canaria, en A. 
Esta labor investigadora, reflexiva y crítica a la vez, le ha permitido además colaborar en proyectos de investigación, como el dirigido por el profesor Suárez Fernández sobre Los Reyes Católicos, e incluso en guiones televisivos como el reciente de Carlos III.

En líneas generales podemos concluir este apartado diciendo que la investigación del profesor Bethéncourt ha sido fecunda, con un recorrido amplio tanto en temas como en métodos, ambos de acuerdo con la nueva historiografía y con el interés que han despertado en los historiadores, atentos siempre a las nuevas corrientes y a lo que sucede en el resto del país y en Europa.

\section{EL UNIVERSITARIO}

A pesar de su preocupación docente e investigadora, ello no quiere decir que el profesor Bethéncourt haya vivido de espaldas a la problemática universitaria sino muy al contrario su papel y su trabajo en el seno de la universidad española ha sido notable, en relación con su labor desde los puestos de responsabilidad donde ha estado y de otras tareas que la universidad le ha conferido, con especial incidencia en la demanda social.

En conjunto podemos decir que $\mathrm{D}$. Antonio ha sido un hombre perseguido por los cargos y por la administración universitaria. Dentro de su propia especialidad le ha correspondido poner en marcha los Departamentos de las Universidades doncle ha estado como catedrático. Ya mencionamos su papel al frente del Departamento de Historia Moderna y Contemporánea de la Universidad de La Laguna, donde no sólo se preocupa por la formación de los alumnos y de crear un grupo de trabajo, sino de dotar a la Biblioteca del mismo de los medios materiales necesarios para convertirla en pionera. Labor similar realiza como Director del Departamento de Historia Moderna de la UNED.

Millares Cantero: Fenomenología de la Restauración en Las Palmas, Las Palmas 1975, págs. 7-26.

${ }_{73}$ Una aproximación al indice de la Revista de Historia de Canarias, en M. F. NúNEZ Muñoz: índices de Revista de Historia Canaria, La Laguna 1986, T. I, págs. VII-XI. 
En relación directa también con la enseñanza no podemos dejar de señalar su labor al frente de la Secretaría de Estudios para Extranjeros de la Universidad de Valladolid, y de la Dirección de la Cátedra de Historia y Estética de la Cinematografía de la Universidad de Valladolid. Su interés por la enseñanza y sus medios lo demostró como Director del Instituto de Ciencias de la Educación de la Universidad de La Laguna.

Del mismo modo ha sido sensible a la labor publicista que deben desarrollar las universidades, demostrado por un lado a partir del Servicio de Publicaciones y Extensión Cultural de Valladolid, y por otro como Director de la Revista de Historia de La Laguna.

La difusión de la enseñanza la ha tenido siempre clara, pues superando obstáculos y distancias ha impartido cursos a lo largo de la geografía española sobre diversos aspectos de la Historia, dentro del marco de la UNED.

Su interés por los grupos de investigación y por la propia enseñanza de la historia le ha llevado a la creación del Seminario de Estudios Históricos de Canarias, en el Centro Asociado de Las Palmas de Gran Canaria, del cual es su Director, y a su participación en Comités Científicos y en la Reforma de los Planes de Estudio, así como en la Comisión de estudios de las Bibliotecas Universitarias.

Desde el plano de la administración universitaria $\mathrm{D}$. Antonio ha pasado por casi todos los estadios de la misma, entre el tiempo pasado en La Laguna y en Madrid. Comenzó por ser secretario de la Facultad de Filosofía y Letras de La Laguna para culminar como Rector de la misma Universidad, después de haber sido nombrado Vicerrector de Extensión Universitaria. Durante su mandato como Rector, el más alto grado al que suele aspirar un profesor universitario, consiguió grandes logros, tanto en dotación como en construcción de nuevos edificios.

Elegido Rector por el claustro de la Universidad de La Laguna, hubo de gobernarla en el difícil período 1974-1979. Su labor fue efectiva por el impulso que consiguió introducir en el desarrollo de la citada universidad. Su preocupación, podemos enjuiciar, se dirigió en una triple dirección: dotar a una universidad desbordada por el número de alumnos de nuevos estudios y de los medios necesarios e imprescindibles a la docencia e investigación, tales como la informatización; ejecutar convenios con los cabildos insulares de Gran Canaria y Tenerife con el fin de obtener suelo y ayuda para la construcción de nuevos edificios; al compás del creci- 
miento en nuevas instalaciones materiales, promovió el fomento y desarrollo de la investigación, con el notable logro de haber obtenido del entonces presidente del Gobierno, Adolfo Suárez, 187 millones con destino al plan de investigación sobre el desarrollo económico canario. También hay que destacar cómo dio paso a la creación de la Universidad Politécnica de Las Palmas, integrando en ella los estudios de Ingeniería, Arquitectura, Agrícola.

La anterior experiencia le llevó en la UNED a ser nombrado primero Vicedecano de la Facultad de Filosofía y Letras y luego Decano de la Facultad de Geografía e Historia.

En esta misma Universidad ha prestado un eficaz servicio a partir de la publicación de la Ley de Reforma Universitaria, pues como miembro del Claustro Constituyente fue eficaz su intervención en la Comisión de redacción de los Estatutos, como en la del Reglamento del Claustro.

Su intensa actividad, su preocupación universitaria y sus esfuerzos y desvelos en pro de la institución en la que ha prestado sus servicios, se han visto recompensados con el otorgamiento de la Medalla de Oro de la Universidad de La Laguna y el nombramiento en la UNED como profesor Emérito.

No quisiéramos concluir esta visión y valoración improvisada, ni el hilo de la trayectoria universitaria de nuestro amigo y maestro Antonio de Bethéncourt y Massieu, sin dejar constancia que la misma, igual que es compartida por nosotros, lo es por el resto de sus discípulos y amigos.

No sabemos si habremos acertado al cien por cien, pero hemos procurado acercarnos lo más posible a la realidad, valorando todo su quehacer universitario. 